\title{
Serum cholecystokinin, basal acid secretion, and infantile pyloric stenosis
}

\author{
I. M. ROGERS, I. K. DRAINER, A. J. DOUGAL, J. BLACK, AND R. LOGAN
}

Stobhill Hospital and the Royal Hospital for Sick Children, Glasgow

SUMMARY The fasting serum cholecystokinin-like activity was measured in 21 infants with pyloric stenosis and in 13 normal controls. No significant difference was found between the two groups. The basal acid secretion was measured by continuously aspirating the previously emptied stomach for one hour. The basal gastric volume and the total and the free acidity were all greater in the pyloric group.

We have previously suggested that increased serum levels of cholecystokinin (CCK) may be responsible for the development and persistence of infantile pyloric stenosis (Rogers et al., 1975). Infants with this condition would have inherited a greater than normal parietal cell mass and, consequently, would have gastric hyperacidity. CCK is released from the duodenum by acid stimulation (Meyer et al., 1970) and causes pyloric muscle contraction (Fisher $e$ t al., 1973). Antral distension due to pyloric hold-up would release gastrin with the likelihood of further acid secretion (Debas et al., 1974), and hence a sequence of events leading to pyloric stenosis of infancy would result (Fig. 1). We measured the serum CCK-like activity from infants with pyloric stenosis and from normal control infants. The basal gastric acid secretion was also measured as far as was ethically possible.

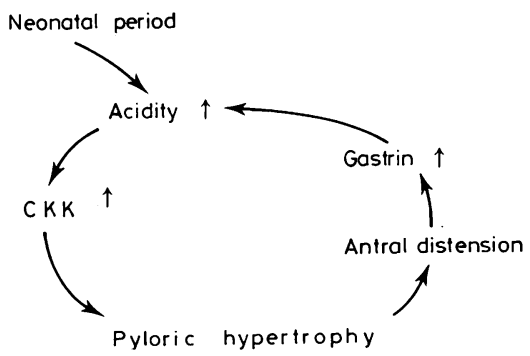

Fig. 1 Sequence of events leading to pyloric stenosis.

\footnotetext{
Ingham Infirmary, South Shields

I. M. ROGERS, consultant surgeon

Stobhill Hospital, Glasgow

A. J. DOUGAL, bacteriologist

Royal Hospital for Sick Children, Glasgow

I. K. DRAINER, consultant paediatric surgeon

J. BLACK, technician in biochemistry

R. LOGAN, consultant biochemist
}

\section{Materials and methods}

21 infants with pyloric stenosis and 13 control infants were studied. The stomach was aspirated dry using a double-lumen nasogastric tube, and $3 \mathrm{ml}$ peripheral blood was obtained by venepuncture. The serum was quickly separated and immediately frozen for subsequent analysis of CCK-like activity.

Serum CCK was determined by radioimmunoassay as described elsewhere (Harvey et al., 1974a). The antiserum used $(\mathrm{OC} 2 / 9)$ was raised against the Cterminal octapeptide of CCK (provided by Dr M. Ondetti, Squibb Institute) and used at a working dilution of 1/30 000. All samples were measured in triplicate, and samples from the paired tests in individual infants were measured in a single assay. However, as at least 3 molecular forms of CCK are present in blood and tissues (Harvey et al., 1974b), and as the assay detects all 3 , it was decided to categorise the CCK values into low, medium, or high range.

The gastric aspirate obtained by one hour's continuous suction was analysed for volume, $\mathrm{pH}$, and free and total acidity. With the control babies the gastric analysis was performed at least $\mathbf{3}$ hours after their last feed.

This project was approved by the ethical committee of the Royal Hospital for Sick Children, Glasgow; informed parental consent was obtained in each case.

\section{Results}

Basal acid secretion. A greater volume of gastric juice was obtained from the pyloric infants. These results were highly signficant $(\mathrm{P}<0 \cdot 01)$ (Fig. 2).

The basal $\mathrm{pH}$ did not differ significantly between the two groups $(P>0 \cdot 1)$ (Fig. 3), but the total 


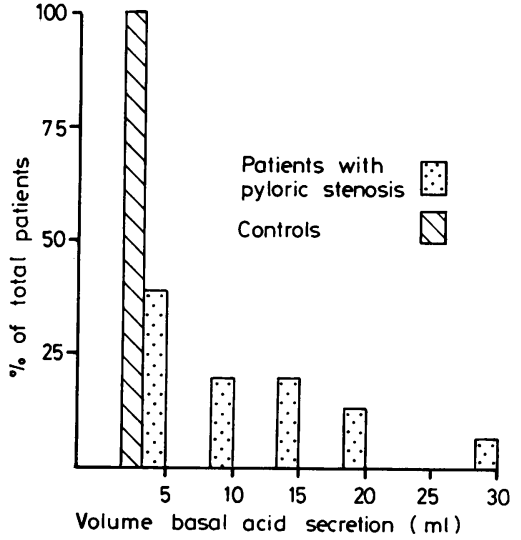

Fig. 2 Basal acid secretion.

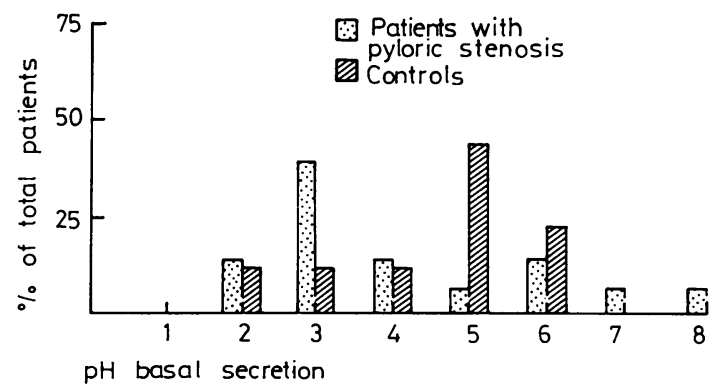

Fig. 3 pH Basal secretion.

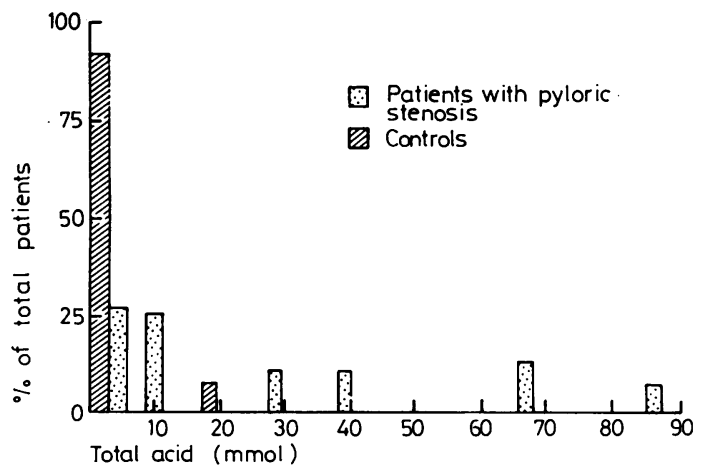

Fig. 4 Total acidity titrated to $\mathrm{pH} 7 \cdot 4$.

$(\mathrm{P}<0.01)$ and the free acidity $(\mathrm{P}<0.05)$ were greater in the pyloric group (Figs 4 and 5).

None of the aspirates from the controls could be titrated to $\mathrm{pH} 3 \cdot 5$. This was usually because too little volume was obtained, or sometimes the starting

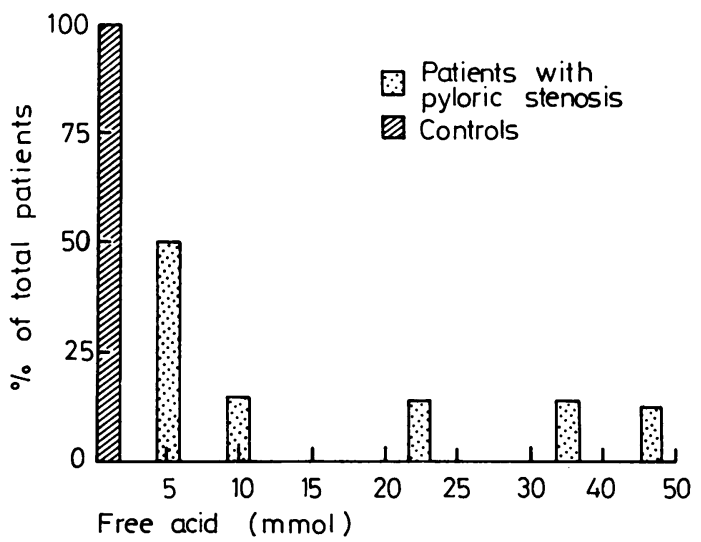

Fig. 5 Free acidity titrated to $\mathrm{pH} 3.5$

pH was already more alkaline than pH $3 \cdot 5$ (Fig. 3). Hence none of these infants had measurable free acidity. Similarly in only one instance could total acidity be measured in the control group and, on that occasion, it was $19 \mathrm{mmol}$ (Fig. 4).

CCK-like activity. The results obtained in both groups were generally higher than those normally found in fasted adults but due to the empirical nature of the values, this could not be verified statistically.

There was little difference in the distribution of the high, medium, or low range of CCK-like activity between the pyloric and the control group although

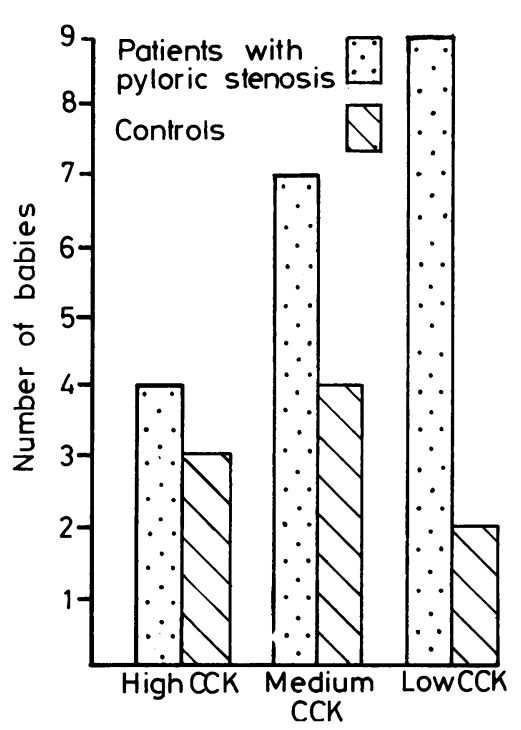

Fig. 6 CCK-like activity. 
the pyloric group tended to accumulate more of the low range values. This tendency was not significant (Fig. 6).

In 6 infants postoperative serum samples were taken between 1 and 2 weeks after surgery. In 5 of these babies the CCK-like activity had increased to a higher range.

\section{Discussion}

The physiological basis for the development of infantile pyloric stenosis is a relatively new area of interest. It is known that the pyloric sphincter contracts in vivo to duodenal acidification (Fisher et al., 1973) and polypeptide hormones, particularly CCK, are thought to be implicated (Isenberg and Csendes, 1972).

Our findings support the view that hyperacidity is present in infants with pyloric stenosis. This opinion presumes that no significant gastric secretion is being lost through the normal pylorus in the control infants. Our findings do not support the suggestion that increased CCK-like activity is implicated in the pathogenesis of this condition.

Our original hypothesis that hypergastrinaemia is responsible for the development and persistence of pyloric stenosis (Rogers et al., 1975) has now been studied by others (Spitz and Zail, 1976; Bleicher et al., 1978). Both studies confirmed the presence of hypergastrinaemia and we concede that our earlier failure to confirm hypergastrinaemia might have been due to technical considerations.

We thank M. D. Moore, biochemist, Stobhill Hospital for statistical and technical assistance, the physicians and surgeons of the Royal Hospital for
Sick Children, Glasgow for allowing study of infants, and John Grant, paediatric surgeon for his encouragement and continuing interest.

\section{References}

Bleicher, M. A., Shandling, B., Zingg, W., Karl, H. W. A., and Track, N. S. (1978). Increased serum immunoreactive gastrin levels in idiopathic hypertrophic pyloric stenosis. Gut, 19, 794-797.

Debas, H. T., Kenturek, S. J., Walshe, J. H., and Grossman, M. I. (1974). Proof of a pyloro-oxyntic reflex for stimulation of acid secretion. Gastroenterology, 66, 526-532.

Fisher, R. S., Lipshutz, W., and Cohen, S. (1973). The hormonal regulation of pyloric sphincter function. Journal of Clinical Investigation, 52, 1289-1296.

Harvey, R. F., Dowsett, L., Hartog, M., and Read, A. E. (1974a). Radioimmunoassay of cholecystokinin/pancreozymin. Gut, 15, 690-699.

Harvey, R. F., Dowsett, L., and Read, A. E. (1974b). Studies on the nature of $\mathrm{CCK} /$ pancreozymin in mallintestinal mucosal extracts (abstract). Gut, 15, 838-839.

Isenberg, J. L., and Csendes, A. (1972). Effect of octapeptide of cholecystokinin on canine pyloric pressure. American Journal of Physiology, 222, 428-431.

Meyer, J. H., Way, L. W., and Grossman, M. I. (1970). Pancreatic bicarbonate response to various acids in the duodenum of the dog. American Journal of Physiology, 219, 964-970.

Rogers, I. M., Drainer, I. K., Moore, M. R., and Buchanan, K. D. (1975). Plasma gastrin in congenital hypertrophic pyloric stenosis. A hypothesis disproved? Archives of Disease in Childhood, 50, 467-471.

Spitz, L., and Zail, S. S. (1976). Serum gastrin levels in congenital hypertrophic pyloric stenosis. Journal of Pediatric Surgery, 11, 33-35.

Correspondence to I. M. Rogers, FRCS, Ingham Infirmary, Westoe Road, South Shields, Tyne and Wear NE33 3PP.

Received 21 November 1978 